Acknowledgements: We thank S. Nakagawa and M. lida for technical assistance.

Disclosure of Interests: Masao Katsushima: None declared, Hiroto Minamino: None declared, Mie Torii: None declared, Motomu Hashimoto Speakers bureau: M.H. receives grants and/or speaker fees from Bristol-Meyers, Eisai, Eli Lilly, and Tanabe Mitsubishi., Grant/research support from: M.H. belongs to the department financially supported by Nagahama City, Shiga, Japan, Toyooka City, Hyogo, Japan and five pharmaceutical companies (Tanabe-Mitsubishi, Chugai, UCB Japan, Ayumi and Asahi-Kasei)

KURAMA cohort study is supported by a grant from Daiichi Sankyo Co. Ltd., Wataru Yamamoto: None declared, Ryu Watanabe Grant/research support from: R.W. belongs to the department that is financially supported by Nagahama City, Shiga, Japan, Toyooka City, Hyogo, Japan and five pharmaceutical companies (Tanabe-Mitsubishi, Chugai, UCB Japan, Ayumi and Asahi-Kasei). KURAMA cohort study is supported by a grant from Daiichi Sankyo Co. Ltd., Kosaku Murakami: None declared, Koichi Murata Grant/ research support from: K.M. belongs to the department that is financially supported by Nagahama City, Shiga, Japan, Toyooka City, Hyogo, Japan and five pharmaceutical companies (Tanabe-Mitsubishi, Chugai, UCB Japan, Ayumi and Asahi-Kasei).

KURAMA cohort study is supported by a grant from Daiichi Sankyo Co. Ltd. Masao Tanaka Grant/research support from: M.T. belongs to the department that is financially supported by Nagahama City, Shiga, Japan, Toyooka City, Hyogo, Japan and five pharmaceutical companies (Tanabe-Mitsubishi, Chugai, UCB Japan, Ayumi and Asahi-Kasei).

KURAMA cohort study is supported by a grant from Daiichi Sankyo Co. Ltd., Hiromu Ito Speakers bureau: H.I. receives a research grant and/or speaker fee from Bristol-Myers, Eisai, Mochida, Taisho, and Asahi-Kasei., Grant/research support from: H.I. belongs to the department that is financially supported by Nagahama City, Shiga, Japan, Toyooka City, Hyogo, Japan and five pharmaceutical companies (Tanabe-Mitsubishi, Chugai, UCB Japan, Ayumi and Asahi-Kasei). KURAMA cohort study is supported by a grant from Daiichi Sankyo Co. Ltd., Akio Morinobu Speakers bureau: A.M. has received speaking fees and/or research grants from Eli Lilly Japan K.K., Ono Pharmaceutical Co., Pfizer Inc., UCB Japan, AbbVie G.K., Asahi Kasei Pharma and Chugai Pharmaceutical Co. Ltd., Grant/research support from: A.M. has received speaking fees and/or research grants from Eli Lilly Japan K.K., Ono Pharmaceutical Co., Pfizer Inc., UCB Japan, AbbVie G.K., Asahi Kasei Pharma and Chugai Pharmaceutical Co. Ltd.

DOI: 10.1136/annrheumdis-2021-eular.2511

\section{POS0545 DISCORDANCE BETWEEN PATIENT'S AND PHYSICIAN'S DISEASE ACTIVITY ASSESSMENT IN RHEUMATOID ARTHRITIS: WHICH DOMAINS CAN INFLUENCE THIS DISCREPANCY WHEN REMISSION IS ACHIEVED?}

L. Moschetti ${ }^{1}, 2$, C. Bazzani ${ }^{1}$, F. Villanova ${ }^{2}$, R. Gorla ${ }^{1}$, F. Franceschini ${ }^{1,2} .{ }^{1} A S S T$

Spedali Civili, Rheumatology and Clinical Immunology Unit, Brescia, Italy;

${ }^{2}$ University of Brescia, Clinical and Experimental Sciences, Brescia, Italy

Background: In daily clinical practice, it is not rare to observe a relevant discordance between patient's global assessment (PGA) and physician's global assessment (PhGA), because of different illness perceptions.

Objectives: To evaluate the presence of PGA/PhGA discrepancy in patients with rheumatoid arthritis (RA) who achieved biological remission and to explore whether this discordance could be influenced by the presence of additional elements affecting patients' quality of life, such as comorbidities, sleep disturbances and psycho-emotional factors.

Methods: Our study included adult RA patients, followed in a single rheumatology centre, fulfilling three out of four Boolean remission criteria: tender joint count $\leq 1$, swollen joint count $\leq 1$ and $C$ reactive protein $\leq 1 \mathrm{mg} / \mathrm{dl}^{1}$. Medical records including demographic data, clinical characteristics and outcomes measures were collected. To evaluate the impact of comorbidities we used the Rheumatic Disease Comorbidity Index (RDCl). Pain assessment, PGA and PhGA were rated on a visual analogue scale $(0-100 \mathrm{~mm})$ on the same day of the clinical evaluation. To analyse the discrepancy between PGA and $\mathrm{PhGA}$, the [PGA-PhGA] variable was calculated, considering as discordant a difference $\geq 30 \mathrm{~mm}$. All the subjects completed the following questionnaires: Health Assessment Questionnaire (HAQ), SF36 Health Survey, State-Trait Anxiety Inventory (STAI-Y1/Y2), Self-rating Depression Scale (SDS Zung) and Insomnia Severity Index (ISI). Statistical analysis was performed to compare concordant and discordant groups.

Results: The study included 90 patients (64 women, 26 men) with a median age of 60 [50-67] and a median RA duration of 10 [5-16] years; $80 \%$ of patients were RF and/or ACPA positive. According to DAS28 (median 1.7 [1.5-2.2]), 90\% of patients achieved remission, 9\% LDA and 1\% MDA. Nevertheless, in $81 \%$ of cases PGA $>$ PhGA and in $33 \%$ [PGA-PhGA] $\geq 30$. The discordant group showed higher median disease activity scores (DAS28: 2.2 [1.9-2.4] vs 1.5 [1.4-1.9], $p<0,001$; SDAl: 6.7 [3.9-8.1] vs 2.0 [0.7-3.2], $p<0.001$ ). No differences were found in gender, age, comorbidities, RA duration, serology and treatment (cs-/bDMARDs). Median prednisone dose was higher in the discordant group (0 [0-21] vs $0[0-7.5] \mathrm{mg} / \mathrm{week}, p: 0,024)$. Data about patient-reported outcomes and differences between two groups are reported in the table 1 .

Conclusion: In our study we found discordance between the global disease assessment reported by patients, although considered in biological remission, and their physicians in $33 \%$ of the cases. As previously described ${ }^{2}$, our data seems to confirm that potential causes for this discordance could be pain due to non-inflammatory processes, functional disability and compromised physical health. In the present study also psychological stress, particularly state anxiety, seems to negatively affect PGA/PhGA concordance. These results confirm the importance, in clinical practice, of exploring and managing inflammatory and non-inflammatory parameters separately, also in patients achieving biological remission.

REFERENCES:

[1] Svensson B et al. BMJ Open. 2013. ${ }^{2}$ Craig ET et al. Arthritis Care Res. 2019.

Table 1. Data are expressed as median ( $1^{\text {st }}-3^{\text {rd }}$ quartile) and compared using Mann-Whitney test.

\begin{tabular}{|c|c|c|c|c|}
\hline $\begin{array}{l}\text { PATIENT-REPORTED } \\
\text { OUTCOMES }\end{array}$ & $\begin{array}{l}\text { PATIENT } \\
\text { NUMBER } \\
=90\end{array}$ & $\begin{array}{c}\text { CONCORDANT } \\
\text { GROUP } \\
\text { (PGA-PhGA) }<30 \\
=60(67 \%)\end{array}$ & $\begin{array}{c}\text { DISCORDANT } \\
\text { GROUP } \\
\begin{array}{c}\text { (PGA-PhGA) } \geq 30 \\
=30(33 \%)\end{array}\end{array}$ & $p<0,05$ \\
\hline PGA, [0-100] & $20(10-40)$ & $10(0-20)$ & $50(37-60)$ & - \\
\hline PhGA, [0-100] & $0(0-10)$ & $0(0-10)$ & $10(0-10)$ & - \\
\hline PGA-PhGA, [0-100] & $10(0-30)$ & $10(0-10)$ & $40(30-52)$ & - \\
\hline VAS pain, $[0-100]$ & $20(10-40)$ & $10(0-20)$ & $50(30-60)$ & $<0,001$ \\
\hline $\mathrm{HAQ},[0-3]$ & $0,13(0-0,50)$ & $0(0-0,25)$ & $0,31(0,09-0,87)$ & $<0,001$ \\
\hline STAI Y1, [20-80] & $36(31-47)$ & $35(30-42)$ & $40(35-51)$ & 0,014 \\
\hline STAIY2, [20-80] & $37(33-45)$ & $37(33-45)$ & $38(33-47)$ & $n s$ \\
\hline SDS ZUNG, [25-100] & $45(40-51)$ & $44(39-49)$ & $48(40-53)$ & $n s$ \\
\hline ISI, [0-28] & $2(2-11)$ & $5(2-11)$ & $8(3-14)$ & $n s$ \\
\hline SF36 Physical, [0-100] & $44(36-52)$ & $48(40-54)$ & $36(28-46)$ & $<0,001$ \\
\hline SF36 Mental, [0-100] & $50(38-56)$ & $51(41-57)$ & $47(33-54)$ & ns \\
\hline
\end{tabular}

Disclosure of Interests: None declared

DOI: 10.1136/annrheumdis-2021-eular.2555

\section{POS0546 RENAL DYSFUNCTION AND METABOLIC CHANGES IN PATIENTS WITH RHEUMATOID ARTHRITIS ARE ASSOCIATED WITH ANGIOPOIETIN-LIKE PROTEIN TYPE 4}

V. Aleksandrov ${ }^{1,2}$, A. Aleksandrov ${ }^{1,2} .{ }^{1}$ Volgograd State Medical University, Department of Hospital Therapy, Volgograd, Russian Federation; ${ }^{2}$ Federal State Budgetary Institution «Research Institute of Clinical and Experimental Rheumatology named after A.B. Zborovsky», Department of clinical and laboratory diagnostics, Volgograd, Russian Federation

Background: Along with chronic inflammation, the development of renal damage in rheumatoid arthritis (RA) is promoted by the presence of metabolic syndrome (MS), which may be an independent risk factor for the progression of chronic kidney disease.

Objectives: To establish a correlation between serum angiopoietin-like protein type 4 (ANGPTL4) and the presence of renal dysfunction and metabolic disorders in RA patients.

Methods: We examined 158 patients with RA (91.8\% - women and $8.2 \%$ - men) aged 21 to 80 years old with an average duration of the disease - $9[4 ; 15]$ years The majority of patients were seropositive for RF-IgM $(57.6 \%)$ and for anti-citrullinated protein antibody (ACPA) $(60.1 \%)$, with an advanced clinical stage $(45.6 \%)$ and moderate activity $(3.2<$ DAS $28 \leq 5.1)$ of the pathological process $(58.2 \%)$. The laboratory examination included the determination of serum concentrations of angiopoietin-like protein type 3 (Human Angiopoietin-like Protein 3 ELISA, Bio Vendor, Czech Republic) and type 4 (RayBio Human ANGPTL4 ELISA Kit; RayBiotech, USA).

To assess renal function in RA patients, the estimated glomerular filtration rate (GFR) was used according to the 2009 CKD-EPI formula. On the basis of GFR measurements, the patients were divided into three groups: I - optimal renal function (> $90 \mathrm{ml} / \mathrm{min})$; II - a slight decrease in renal function $(89-60 \mathrm{ml} / \mathrm{min})$; III reduced renal function $(<59 \mathrm{ml} / \mathrm{min})$.

A combination of the increased blood pressure $(\geq 140 / 90 \mathrm{mmHg})$, the increased triglyceride levels $(\geq 1.7 \mathrm{mmol} / \mathrm{L})$, and the impaired carbohydrate metabolism (increased fasting plasma glucose $\geq 6.1 \mathrm{mmol} / \mathrm{L}$ ) with a background of central obesity (waist circumference $>94 \mathrm{~cm}$ in men and $>80 \mathrm{~cm}$ in women) served as the basis for inclusion into the group of RA patients with signs of MS.

Results: A multivariate analysis of variance was performed comparing ANGPTL indices depending on GFR in the groups of RA patients without signs of MS and 